\title{
EL VERBO Y LA PRODUCCIÓN DISCURSIVA DE LOS NIÑOS COSTARRICENSES DE 2 A 4 AÑOS DE EDAD
}

\author{
The verb and the discursive production \\ of Costa Rican children from 2 to 4 years old
}

Marielos Murillo Rojas ${ }^{1}$

\begin{abstract}
RESUMEN
El verbo es una forma sintáctica, nuclear para la conversación, que posee una densa morfología (tiempo, aspecto, modo, voz, persona y número), por lo que es un referente básico al analizar el desarrollo del lenguaje de los niños. El presente artículo, de naturaleza descriptivo-transversal, tiene como objetivo identificar la acción verbal y las formas verbales temporales empleadas por 38 de niños costarricenses de 2 a 4 años en la producción de textos orales, elicitados a partir de narraciones de eventos ligados al contexto escolar y familiar, así como a la narración de cuentos infantiles.
\end{abstract}

Palabras clave: Desarrollo del lenguaje, marcadores morfológicos, tiempo verbal, aspecto verbal.

\section{SUMMARY}

The verb is a syntactic form, nuclear for the conversation, that has a dense morphology (time, aspect, mode, voice, person and number), reason why it is a basic reference when analyzing the development of the language of the children. This descriptive-transversal article aims to identify the verbal action and temporal verbal forms used by 38 Costa Rican children, aged 2 to 4 years in the production of oral texts, elicited from narratives events linked to the school and family context, and to the narration of children's stories.

Key Words: Language development, morphological markers, time and verbal aspect.

\section{Introducción}

Los estudios sobre el desarrollo del lenguaje infantil interesan a lingüistas, psicólogos, educadores, pediatras y a quienes se ocupan de elaborar sistemas de medida o instrumentos de diagnóstico que permitan describir el nivel de desempeño de los niños en diferentes componentes del lenguaje (léxico, morfosintáctico, discursivo, fonológico).

En el ámbito internacional se ha producido una gran cantidad de investigaciones de corte transversal y longitudinal que ofrecen datos valiosísimos para conocer los procesos evolutivos en la adquisición de la lengua en niños hispanohablantes y de otras variedades lingüísticas. Acerca de la

\footnotetext{
${ }^{1}$ Universidad de Costa Rica. Escuela de Formación Docente. Costa Rica.

Correo electrónico: marielosmuro@gmail.com

Recepción: 17/04/2017_Aceptación: 29/03/2019.
} 
adquisición de la lengua en niños costarricenses, podría afirmarse que se han abierto sendas, pero no se cuenta con datos suficientes que permitan plantear una descripción detallada de la emergencia del lenguaje en esta población; por tanto, sería una tarea azarosa valorar los procesos de desarrollo lingüístico de nuestros niños con la información actual.

La presente investigación, basada en el corpus lingüístico recopilado para el proyecto "Perfil léxico del niño costarricense de 2 a 4 años", inscrito en la Vicerrectoría de Investigación de la Universidad de Costa Rica, tiene como objetivo aportar a la descripción de las distintas formas temporales del verbo usadas en el discurso de un grupo de niños costarricenses de 2 a 4 años y en la identificación de los tipos de verbos utilizados por estos niños en su discurso, de conformidad con la taxonomía de Cortés y Vila (1991), basada en Vendler (1967) y usada por Aguado (2002).

El corpus lingüístico objeto de estudio fue aportado por 38 niños que asistieron a instituciones privadas de educación preescolar durante los ciclos lectivos de 2014 y 2015, con un desarrollo del lenguaje esperado para su edad -según la valoración de sus maestras- y sin problemas auditivos o visuales. La muestra se distribuyó en cuatro rangos de edad: a) de 2 años a 2 años y 6 meses, b) de 2 años y 7 meses a 3 años, c) de 3 años a 3 años y 6 meses y d) de 3 y 7 meses a 4 años; lo anterior con el objetivo de organizar el análisis de esta manera.

\section{Desarrollo de la referencia temporal en el niño}

La temporalidad, siguiendo a Berman y Slobin (1994), se define como la expresión de la ubicación de los eventos en una línea del tiempo, de relaciones temporales entre eventos y circunscripción temporal de los acontecimientos. En el discurso, las marcas temporales se observan mediante: morfemas gramaticales, oraciones que marquen tiempos verbales, adverbios, conectores y estrategias discursivas, tal como la disposición temporal de eventos en un texto narrativo.

Los adverbios, conectores temporales, las flexiones de morfología verbal y el orden de los enunciados son diferentes recursos que usan las lenguas para gramaticalizar las relaciones temporales. Al poseer la lengua la categoría verbal, los morfemas verbales expresan habitualmente valores temporales, aspectuales y modales.

Para efectos de la presente investigación, se consideran únicamente las marcas temporales presentes en los verbos y en las perífrasis verbales producidas por niños de 2 a 4 años. Los tiempos verbales de interés son presente, pasado y futuro; siguiendo el camino ya recorrido por otras investigaciones, se consideran también las nociones aspectuales del presente y del pretérito. 
Respecto de la lengua española, Gili (1972), Cortés y Vila (1991), Sebastián (1991), Rodenas, Brito y Carranza (1991), Villamil-Forastieri (1991), Aguado (2002), Fernández-Pérez (2006) y Pineda (2014), entre otros se han ocupado del tiempo y del aspecto en la producción discursiva de niños menores de 4 años. De estas investigaciones, se reseñan los hallazgos más sobresalientes y que sirven de sustento al presente estudio.

Gili (1972) publica el clásico estudio Funciones gramaticales en el habla infantil. Esta investigación se basó en un corpus transversal de niños entre 4 y 11 años en el que se describen algunas formas lingüísticas del español. Como parte de sus resultados, las formas verbales más utilizadas por los niños son el presente y el pretérito de indicativo, esto debido a que el infante habla sobre lo que ve, lo que está haciendo y lo que hizo en un tiempo reciente. Igualmente, el autor indica que los niños usan el futuro mediante perífrasis "ir a + infinitivo" y por adverbios, pero a los 10 años empiezan a producir el futuro de forma sistemática; antes de esa edad su valor es modal y no temporal.

El artículo "Uso y función de las formas temporales en el habla infantil” (Cortés y Vila, 1991), estudio empírico con tres niños, una monolingüe en catalán y dos bilingües en españolcatalán, consta de tres partes: la primera describe la aparición de las formas temporales en español y catalán, entre los dos y tres años de edad; la segunda cuestiona la primacía del aspecto sobre el tiempo, en el segundo año de vida; la tercera es un estudio longitudinal que explica la incorporación de las marcas temporales en el proceso de adquisición del lenguaje.

Los autores señalan que la mayoría de trabajos sobre adquisición de la referencia temporal define el sistema temporal-aspectual desde una perspectiva semántico-referencial, y distinguido entre tiempo gramatical, aspecto y tipo de situación. El tiempo gramatical se entiende como la gramaticalización de las relaciones, anterioridad, simultaneidad y posterioridad respecto de un punto determinado del continuum, el cual corresponde convencionalmente al presente. Por aspecto se comprende la gramaticalización de las diferentes perspectivas que un hablante puede tomar al referirse a un proceso. Una situación puede ser vista desde una gran diversidad de distinciones: simultaneidad, inclusión, sobreposición, etc. Las distinciones que tienden a formalizarse son: perfectividad / imperfectividad, progresividad / no progresividad. Además, el propio ítem verbal aporta información en cuanto al proceso; de esta forma se acepta, en general, que existe una distinción entre verbos de actividad y de estado.

Los verbos de estado describen cualidades o situaciones que no sufren cambios a lo largo del tiempo (gustar, tener, ser, etc.). Los verbos dinámicos describen situaciones que necesariamente implican un cambio y representan sus fases, distintas unas de otras. Vendler (1967), citado por 
Cortés y Vila (1991), distingue entre verbos de cambios de estado, verbos puntuales, verbos durativos y verbos de actividad. Los verbos de cambio de estado son aquellos que comportan una transformación por medio de la cual un objeto cambia de estado y llega a un estado final. Los verbos puntuales o de consecución son aquellos que una vez iniciada la acción ya no puede pararse: romper, caer, conseguir. Los verbos durativos o de realización responden a la idea de que una vez iniciada la situación se puede interrumpir antes de llegar a su final: construir, escribir un libro, etc. Por su parte, los verbos de actividad representan una situación que implica una transformación, pero no un resultado final; son situaciones que pueden continuar indefinidamente: correr, saltar, comer, jugar, etc.

Si bien este estudio analiza el sistema referencial temporal del catalán y del castellano, para efectos de esta investigación se toman únicamente los datos relativos al castellano. En español se debe distinguir entre el sistema de tiempos gramaticales y la gramaticalización mediante la perífrasis. Todos los tiempos simples o perfectos tienen sus correspondientes tiempos progresivos, formados mediante "estar + gerundio". El indefinido o perfecto se puede emplear para referirse a situaciones de pasado reciente y alterna con el uso del pretérito perfecto. El pretérito imperfecto tiene un valor de presente respecto al pasado. El futuro se codifica en acciones de futuro inmediato y futuro lejano. En español, además, se cuenta con la forma perifrástica "ir a + infinitivo" con la que se puede referenciar una acción que comienza a efectuarse, ya sea en la intención o en la realidad. El léxico también expresa distinciones aspectuales y temporales; por ejemplo, mediante adverbios temporales y marcas secuenciales (primero, segundo, después, etc.).

Para el análisis de los datos, se consideraron los siguientes tópicos: descripción de la secuencia de la aparición de las marcas temporales entre los 2 y 3 años de edad; la función de las primeras marcas temporales y aspectuales durante el segundo año de vida, a partir de las categorías: forma del verbo, codificación de tipo de predicado (verbos de estado, de actividad, de realización y de consecución), y distinciones aspectuales no flexionadas morfológicamente (consecución, terminación, incoacción, inminencia, iteración, recurrencia, duración, puntualidad, perfección, hábito, etc.); expresiones lexicales adverbiales temporales, incluidos adverbios y conjunciones, situación en el tiempo real.

Respecto de la secuencia de aparición de las marcas temporales, el imperfecto aparece muy pronto, al compararlo con otros estudios; el pretérito perfecto es la primera forma de pasado que usan en los sujetos estudiados. Las formas de futuro emergen casi simultáneamente, la simple y la perifrástica. 
En relación con la función de las primeras marcas temporales, se encuentra que, al inicio, los tiempos que codifican perfectividad se usan más con verbos de cambio de estado y los que codifican imperfectividad se usan con verbos de estado o de actividad. No obstante, esta situación es momentánea, pues con el correr del tiempo esas diferencias se diluyen, y los niños utilizan verbos de estado y de actividad con flexiones distintas. Al respecto, Cortés y Vila mencionan:

Estos datos permiten relativizar la explicación de la incorporación de marcas temporales verbales en base a una relevancia de significados. A pesar de que parece existir una tendencia a utilizar determinados tiempos gramaticales con un tipo determinado de verbos, nuestros sujetos emplean tiempos gramaticales con verbos que semánticamente no le son afines (1991, p. 31).

En fin, los niños estudiados distinguen entre presente y no presente, e incorporan antes de los tres años formas temporales para el pasado y para el futuro. Asimismo, los datos de esta investigación apoyan la hipótesis de que el tiempo y el aspecto se construyen simultáneamente.

Sebastián (1991), en el estudio El desarrollo del sistema de referencia temporal en español: Un paseo por la morfología verbal, trabajó con niños de 3, 4, 5 y 9 años y un grupo de adultos; se utilizaron como recurso de elicitación las imágenes del cuento Frog, where are you? De conformidad con los intereses de la presente investigación y por ser uno de los rangos de edad que ella abarca, se consideran únicamente los resultados que corresponden a los niños de 3 años a 3 años y 11 meses. Los datos muestran que los 12 niños españoles participantes de 3 años de edad hacen uso de todas las formas verbales a excepción del pasado perfecto (había comido) y del pasado perfectivo progresivo (estuvo comiendo). Además, este subgrupo utilizó con mayor proporción, respecto de los otros, el presente perfecto, esto para indicar una acción o un estado final visible para los participantes: “(...) y aquí ha subido y entonces el niño se sube a un ciervo” (p. 188).

Respecto del tiempo verbal, los niños narran el cuento en presente y en pasado, pero es el presente el tiempo predominante. El presente parece ser una forma que se utiliza para describir, acompañado, muchas veces, de la partícula locativa aquí. En lo concerniente a las formas progresivas, tanto el presente como el imperfecto progresivo son mucho más frecuentes en los niños de $3(6,6 \%)$ y 4 años $(6,3 \%)$, respecto de los niños de 9 años y los adultos participantes. La recurrencia de las formas progresivas en los niños pequeños se explica por el hecho de que la utilizan para describir los dibujos que responden a la secuencia del cuento utilizado.

Por otra parte, los contrastes entre perfectivo e imperfectivo son muy frecuentes desde los 3 años. Los informantes utilizan el perfectivo para indicar acciones completas y el imperfectivo para 
indicar estados (existencia, locación, deseos) o sucesos durativos: “y cuando se cayó le gritó y le cogió, y le llamaba a la rana y no le oía” (Sebastián, 1991, p. 192).

Finalmente, la autora acota que el uso infantil de cualquier forma verbal no refleja necesariamente su adquisición de forma definitiva, ni que las funciones atribuidas a esa forma, por parte de los niños, sean las mismas que las del adulto. Además, resalta que la complejidad del sistema verbal español no dificulta su adquisición, sino que, al contrario, parece estimular la adquisición de los marcadores aspectuales y temporales.

Rodenas, Brito y Carranza (1991), en el artículo "La referencia temporal de futuro en el lenguaje espontáneo infantil", analizan el patrón evolutivo del uso de expresiones con valor de futuro en una muestra de 84 niños de dos años y seis meses a 13 años, repartidos en nueve grupos. Las muestras analizadas son de habla espontánea, recopiladas en escuelas públicas de la ciudad de Alicante. Los autores señalan que los niños aprenden a expresar los conceptos temporales teniendo en cuenta dos aspectos: el modo en que su lengua nativa codifica la información temporal y la construcción de un sistema de reglas que les permita comprender y producir expresiones referidas al tiempo. De acuerdo con Smith (1980), citado por estos autores, la estructura necesaria para referirse a acontecimientos se logra aplicando tres nociones temporales: a) el momento del habla (ST speech time), intervalo del tiempo en que se produce un acto de habla; b) el tiempo del acontecimiento (ET event time), la diferencia de tiempo entre una situación específica y el momento del habla; c) el tiempo de referencia (RT reference time), el contexto temporal que se identifica con la expresión. La representación verbal del futuro sería la capacidad de situar un acontecimiento que potencialmente está por venir en un marco de referencia concreto. Dadas las evidencias recopiladas por las investigaciones en diferentes lenguas, el valor de futuro parece presentar un grado de dificultad mayor que las formas que hacen referencia al pasado y al presente. También, se acota que en español existe multitud de expresiones verbales que hacen referencia a sucesos futuros, esta variedad obliga al hablante a elegir cuál forma utilizar y, consecuentemente, puede ser causa de su mayor dificultad.

Los resultados muestran que los niños pequeños usan con mucha más frecuencia las formas de futuro con valor temporal inmediato y que, conforme avanza la edad, va aumentando la frecuencia de uso de expresiones con valor temporal no inmediato.

El futuro absoluto es poco utilizado en todos los grupos, incluyendo a los adultos; parece que los niños españoles prefieren usar otras formas verbales para referirse a sucesos futuros. El presente de indicativo con valor de futuro es usado por los niños de 2 y 3 años; sin embargo, la perífrasis ir a + infinitivo es la forma que más utilizan los informantes para referirse a 
acontecimientos futuros. También se utiliza el imperativo en las primeras edades, sobre todo para dar órdenes, hacer preguntas y prohibir; empero, este uso muestra una tendencia decreciente con la edad. Por otra parte, el presente de subjuntivo es una de las formas verbales que manifiesta una clara tendencia a crecer con la edad; a partir de los 4-5 años todos los sujetos utilizan alguna vez este tiempo verbal.

El pretérito imperfecto de indicativo es utilizado con valor de futuro en dos sentidos: hipotético (si tuviera dinero compraba un coche) e imaginativo (yo era el bueno y tú eras el malo), el cual aparece a los tres años y se incrementa a los cuatro; a los cinco años, tiene una utilización máxima y prácticamente desaparece a los seis años.

El condicional, por su parte, forma que añade al valor de futuro la idea de probabilidad, es de uso tardío, pues aparece a los cinco años y es usado por el $40 \%$ de los niños de la muestra.

El infinitivo se considera una forma verbal en continua tensión hacia el futuro, pero dado que no lleva morfológicamente ninguna indicación temporal se debe recurrir al contexto para identificar el tiempo de la acción del verbo. Los niños pequeños lo usan fundamentalmente en sustitución del imperativo y acompañando a verbos modales.

En suma, el niño utiliza la forma de futuro absoluto para expresar una acción futura de la cual no está seguro o tiene dudas, mientras que emplea el presente o la perífrasis "ir a + infinitivo" cuando tiene certeza de que la acción va a ocurrir: esta tarde toca la clase de lengua / esta tarde tocará (probablemente) la clase de lengua. Los datos que ofrece esta investigación parecen mostrar que el desarrollo del lenguaje temporal no termina con la segunda infancia, sino que se prolonga quizá hasta la adolescencia.

Villamil-Forastieri (1991), en el artículo "La adquisición de aspecto y tiempo en niños puertorriqueños entre las edades de 1;10 a 3;2 años", trabaja con una muestra de 14 niños, quienes mediante conversaciones guiadas aportaron texto relativo a objetos que aparecían en láminas diseñadas para ese propósito, narraron eventos acaecidos en su pasado o comentaron lo que sucedía en el momento de la grabación. Esta autora conceptualiza el tiempo como el momento de una situación dada de habla y la proyección temporal que el hablante hace en su enunciación. El aspecto se refiere al orden temporal interno de una acción específica; por ejemplo, en el pretérito imperfecto se presume una acción simultánea a la acción denotada en el enunciado, contrario al pretérito perfecto que hace referencia a una acción terminada.

Se presenta una disertación respecto de las dos vertientes en torno a la adquisición del tiempo y del aspecto: una documenta que el aspecto surge con anterioridad al tiempo, ya que los 
verbos con terminación de acción clara se codifican primero con el pasado. La segunda señala que están presentes simultáneamente diferentes clases de verbos y tiempos verbales, pero que las flexiones de pasado ocurren preferentemente en las categorías de verbos desinentes. Por ejemplo, si una acción es continua, se usaría una forma progresiva; si una acción tiene una terminación clara, se usaría el pretérito indefinido.

Como parte de los resultados encontrados en esta investigación se analizan los verbos en términos de categorías verbales y la cantidad de verbos emitidos en cada una de ellas.

Los verbos desinentes y los verbos de actividad son los más utilizados. Los eventos de estado son menos frecuentes en uso y cantidad. Respecto a la distribución porcentual los niños utilizan un $40 \%$ de verbos desinentes, $44 \%$ verbos de actividad y $16 \%$ verbos de estado. El uso principal de los verbos desinentes es en imperativo, seguido del presente, a continuación el pretérito indefinido y, por último, el infinitivo.

Los tiempos verbales del presente ocupan la posición mayoritaria respecto del tiempo pasado. Se usa el imperativo, el presente y el progresivo presente. En pasado el pretérito indefinido es el más usado. En este estudio no se hace referencia al futuro.

Fernández-Pérez (2006), en el artículo "Usos verbales y adquisición de la gramática. Construcciones y procesos en el habla infantil", pone de manifiesto el valor de los usos verbales en el período infantil y presenta una profunda reflexión acerca de la necesidad de acercarse al lenguaje infantil de manera objetiva, con una mirada hacia aquello que tienen de particular los sistemas de construcción en las etapas iniciales de la adquisición. Algunos autores citados en este estudio, tales como Tomasello y P.J. Brooks (1999), afirman que los distintos tipos de construcción que elaboran los niños durante las primeras etapas son las contrapartes comunicativas de las escenas de la realidad cotidiana que conceptualizan y quieren transmitir, por lo que la autora del artículo recalca que la presencia de ciertas constantes en los mecanismos de desarrollo, la posibilidad de establecer niveles y etapas, y los condicionamientos que envuelven la comunicación infantil son pruebas de que existen pautas de emergencia y avance verbal.

Las fases, denominadas holofrástica, telegráfica y sintáctica, adecuadamente reformuladas, sintonizan con la necesidad de contemplar el desarrollo gramatical de manera sistémica, respecto de los otros componentes de la lengua. Centrándonos en la temática que nos ocupa, los verbos son considerados como elementos clave en el caudal léxico para la aparición de las primeras construcciones en sentido estricto: "En torno a acciones y acontecimientos se edifican estructuras argumentales, primero imitadas y gradualmente controladas a través de la selección de 
constituyentes, del orden de los elementos y de las categorías morfológicas” (Fernández-Pérez, 2006, p. 335).

Los niños desde los 18 meses realizan combinaciones de palabras y a partir de los 24 meses se visualizan marcas sintácticas en las construcciones verbales. Además, se acota que a mayor número de verbos usados, mayor desarrollo sintáctico. El léxico verbal es medida de progreso construccional y constituye una pauta para delinear tendencias de avance y trazar perfiles de desarrollo lingüístico.

Aguado (2002) presenta una obra básica para los estudios del lenguaje infantil, El desarrollo del lenguaje de 0 a 3 años, en la cual hace una amplia reseña del lenguaje infantil, transitando por las etapas prelingüística y lingüística, y el desarrollo de cada uno de los componentes de la lengua (fonológico, semántico y morfosintáctico). Como parte del desarrollo semántico, el autor expone la adquisición del vocabulario (nombres, verbos y adjetivos), apartado que sirve de sustento a la presente investigación. La segunda parte de la obra constituye un estudio transversal del lenguaje del niño de dos años y medio, y se presenta un perfil léxico y morfosintáctico para este grupo etario.

El objetivo de Aguado es realizar una descripción pormenorizada del lenguaje del niño antes de entrar al segundo ciclo de la educación infantil, según la organización curricular española. Este estudio tomó los aportes de 35 niños de 2 años y 6 meses aproximadamente. El material se recoge en un ambiente denominado "La casita", espacio apto para el juego y la elicitación de textos orales, con apoyo de un adulto cercano.

Respecto de los verbos, se agruparon de conformidad con la respectiva unidad léxica y se clasificaron en función de la acción verbal, siguiendo a Cortés y Vila (1991) y a Vendler (1967). Además, se identificó el número total de todas las formas temporales empleadas, con exclusión del imperativo y los determinantes verbales que eran parte de fórmulas dialógicas. Para el análisis de los verbos, se incluyeron las perífrasis: ir a + infinitivo, las compuestas por gerundio y las que llevan participio pasado. Incluso, se incluyeron las formas no personales de gerundio, infinitivo y participio.

En relación con los tiempos y modos verbales, se destaca que las formas verbales más usadas por los niños son presente, pasado y futuro de indicativo. El presente es el tiempo más empleado $(64,39 \%$ de todos los verbos) y se recurre al presente progresivo $(0,97 \%)$ para los verbos de actividad, debido a que representa la continuidad del momento en que se realiza la acción. El presente se desliza hacia el pasado inmediato (pretérito perfecto) y el futuro inminente (ir a + infinitivo). El pretérito perfecto compuesto es la forma del pasado más utilizada con un $8,93 \%$ de 
apariciones en el corpus; el pretérito imperfecto representa el 1,21\% y en el $70 \%$ de las veces de su aparición se produce con verbo de estado. La perífrasis "ir a + infinitivo" representa un 6,76 \% y en un $44,64 \%$ de las veces se forma con verbos de cambio de estado puntual (se va a levantar).

En este estudio se constata que los verbos de estado se emplean en presente de indicativo; mientras los verbos de cambio de estado puntual, en perfecto compuesto y con un uso predominante de participios pasados, como indicadores de la acción recién terminada; los verbos de actividad, con formas de continuidad (presente progresivo, gerundio y futuro).

En suma, los tiempos verbales más empleados en esta investigación son el presente, el pretérito perfecto compuesto (he comido) y la perífrasis con valor de futuro "ir a + infinitivo". Se comprueba en este estudio que existe relación entre las formas verbales y la acción verbal:

Se propone, como explicación, un aprendizaje de las formas verbales como expresiones referenciales de un acontecimiento concreto a partir de las que el niño, a causa de las descoordinaciones en sus interacciones con el adulto, va construyendo con ayuda de su interlocutor más experto la categoría del verbo (Aguado, 2002, pp. 243-244).

Pineda-Morales (2014), en su tesis doctoral denominada El tiempo y el aspecto en el español temprano de Venezuela y España, analiza la adquisición del tiempo y aspecto en niños venezolanos y españoles. Este estudio se basa en dos corpus: el primero es longitudinal, correspondiente a textos orales de una niña madrileña; el segundo, transversal de dos regiones de Venezuela, Mérida y Valencia, para un total de 4 grabaciones, de niños de 2 años y 7 meses. Las muestras siguen el mismo tipo de procedimiento de recolección de la información: narración de cuentos y diálogos en situaciones lúdicas y reales. El análisis de la gramaticalización del aspecto y el tiempo se realiza desde la perspectiva morfológica. Al tratarse de un enfoque cualitativo, los datos se analizaron manualmente y de cada transcripción se consideraron los ejemplos de verbos, adverbios y otros elementos morfosintácticos.

En términos generales, se concluye que los niños eligen el presente como referencia temporal y la categorización aspectual para fijar las características de las situaciones.

Se encuentran tres aspectos en el tiempo pasado, considerando que los niños se refieren a situaciones ocurridas pasadas: el imperfectivo (acción inacabada), el imperfectivo en progreso (acción inacabada en progreso) y el perfectivo pasado (acción ocurrida en pasado). Sin embargo, dependiendo del tipo de discurso, contexto real o narrativo, y de los adverbios, no todas son acciones ocurridas en el ayer. Además, se presentan algunos casos en que los niños usan el modo subjuntivo y se nota la ausencia de formas verbales más complejas. 
En dicha investigación se demuestra que el tipo de discurso determina el uso de ciertas formas verbales y, por consiguiente, aspectuales. Como ejemplos, se tiene el perfectivo "canté" que, según su contexto, puede ser perfectivo presente o perfectivo pasado. En relación al imperfectivo, en el corpus de la niña española, aparece usado en las historias narradas y en hechos reales pasados. En la muestra de niños venezolanos, solo un niño lo usó en contextos narrativos, los otros niños no usan este aspecto.

Finalmente, se demuestra que los niños venezolanos y españoles presentan diferencias entre el uso del pretérito simple y compuesto. Por consiguiente, se asume que el entorno lingüístico del niño influye en su producción, específicamente en su relación con el adulto.

Las investigaciones citadas aportan información metodológica y hallazgos científicos que permiten comparar los resultados obtenidos entre niños costarricenses y de otras realidades socioculturales tanto en Europa como en América. En este sentido, se sigue la línea general de recopilación de textos narrativos y eventos espontáneos de habla para formar el corpus, como objeto de estudio; se usa la taxonomía de Vendler (1967), a fin de valorar la función verbal y, para la identificación de las formas temporales se toman como base los parámetros metodológicos de Aguado (2002). Finalmente, en el análisis se incorporan, desde un enfoque comparativo, los resultados obtenidos en las investigaciones reseñadas.

\section{Metodología}

La presente investigación descriptivo-transversal parte del principio de que la socialización y la adquisición del lenguaje están dentro del mismo proceso; por tanto, se hace necesario observar y registrar la producción lingüística en diferentes prácticas sociales de interacción en el niño. En consecuencia, se elige la narración de eventos presentes ligados al contexto escolar y familiar, así como cuentos, películas, programas de televisión o eventos que interesen al niño, como situaciones idóneas para recopilar la información requerida.

Se considera, al igual que Prago (2004), que:

(...) la narración es un género discursivo idóneo para analizar la adquisición del lenguaje como un proceso enraizado en la socialización dado que (...) el género narrativo es un punto de encuentro entre los niveles léxico, gramatical, pragmático, cognitivo y social. Y, por lo tanto, constituye un contexto discursivo natural para analizar la adquisición del lenguaje" (p. 100). 
El corpus estuvo formado por textos orales producidos por un total de 38 niños, divididos en cuatro rangos de edad: a) de los 2 años a los 2 años y seis meses; b) de los 2 años y siete meses a $\operatorname{los} 3$ años; c) de los 3 años a los 3 años y seis meses y d) de los 3 años y siete meses a los 4 años cumplidos, quienes asistían durante el año 2014 y 2015 a alguna modalidad de la educación preescolar costarricense.

Los textos fueron transcritos mediante el sistema CHAT del proyecto Child Language Data Exchange System, de Briam Mac Whinney. Para el procesamiento de los datos se utilizó el sistema CLAN (Child Language Analysis Programs), que ofrece un listado de palabras con la frecuencia respectiva, así como la recuperación de los contextos lingüísticos que requiera el investigador. Posteriormente, cada palabra morfológica del discurso se lematiza en la correspondiente unidad léxica. Se forman, por tanto, cuatro grupos de léxico básico que incluyen sustantivos, adjetivos, verbos y adverbios. No obstante, para la presente entrega interesa únicamente el material correspondiente a los verbos.

Con el propósito de identificar la tipología verbal, se sigue la taxonomía de Cortés y Vila (1991), basada en Vendler (1967), descrita en páginas anteriores, y usada por Aguado (2002). De esta forma, se tienen verbos de estado y verbos de no estado o dinámicos. Los verbos dinámicos se clasifican en dos tipos: los puntuales y durativos.

Además, se identifica el total de formas temporales empleadas por los niños. Siguiendo las recomendaciones de Aguado (2002) y en virtud de las características del corpus no se contabiliza el imperativo dentro de los verbos, pues la mayor parte de las veces sustituyen a un enunciado; tampoco se toman en cuenta verbos que forman parte de fórmulas dialógicas o conectores pragmáticos (digamos, oiga, vea, veamos). Para efectos de la clasificación de los verbos en tiempos y modos se incluye la perífrasis "ir a + infinitivo" por ser una forma arraigada de formar el futuro inmediato. Además, se consideraron otras perífrasis formadas con infinitivo, gerundio y participio, a partir del análisis de los contextos de uso, recuperados mediante el comando kwal del sistema CLAN.

\section{Análisis de datos}

El análisis se organiza por grupos de edad, a saber: grupo N. ${ }^{\circ}$, corpus de los 2 años a los 2 años y seis meses; grupo N. ${ }^{\circ} 2$, corpus de los 2 años y 7 meses a los 3 años; grupo N. ${ }^{\circ} 3$, corpus de los 3 años a los 3 años y 6 meses, y grupo N. ${ }^{\circ} 4$, corpus de los 3 años y 7 meses a los 4 años cumplidos. En adelante, se denominarán grupo N. ${ }^{\circ} 1$, grupo N. ${ }^{\circ} 2$, grupo N.o 3 y grupo N. ${ }^{\circ} 4$. 
Para cada grupo se obtiene un vocabulario básico, inventario lematizado, del cual se extraen los sustantivos, adjetivos, verbos y adverbios, con la siguiente distribución.

Grupo n. ${ }^{0}$ 1: 321 sustantivos, 129 verbos (correspondientes a 346 formas discursivas distintas, dato pertinente para el presente estudio), 62 adjetivos y 31 adverbios.

Grupo n. ${ }^{\circ}$ 2: 228 sustantivos, 159 verbos (correspondientes a 399 formas discursivas distintas, dato pertinente para el presente estudio), 63 adjetivos y 40 adverbios.

Grupo n. ${ }^{\circ}$ 3: 180 sustantivos, 108 verbos (correspondientes a 237 formas discursivas distintas, dato pertinente para el presente estudio), 52 adjetivos y 34 adverbios.

Grupo n. ${ }^{0}$ 4: 421 sustantivos, 215 verbos (correspondientes a 602 formas discursivas distintas, dato pertinente para el presente estudio), 105 adjetivos y 40 adverbios.

Para efectos del presente estudio, tal como se indicó anteriormente, se considera únicamente la información relativa a los lemas verbales y sus correspondientes formas discursivas conjugadas.

\subsection{Grupo N. ${ }^{\circ} 1$ : Niños de 2 años a 2 años y 6 meses}

\subsubsection{Tiempos y modos verbales}

Identificadas las 346 formas verbales conjugadas verbales presentes en el corpus, las herramientas informáticas posibilitaron la búsqueda de cada palabra en su contexto de aparición y la recuperación de las perífrasis necesarias, así como la identificación de las funciones verbales y su relación con el tipo de verbo utilizado.

El tiempo en que discurre la acción expresada mediante morfemas verbales se resume de la siguiente forma: a) modo indicativo: presente $38,44 \%$, pretérito perfecto $21,68 \%$, pretérito imperfecto 4,91\%, futuro próximo formado por la perífrasis "ir a + infinitivo" $6,07 \%$; b) modo subjuntivo: presente $2,89 \%$, pretérito imperfecto $0,87 \%$; c) formas no personales: infinitivo 10,12 $\%$ (no se incluyen los infinitivos que forman parte de la perífrasis "ir a + infinitivo"), gerundio 3,76

$\%$ y participio pasado 6,07 \%. Además, se identificó el presente progresivo formado mediante la perífrasis verbal "estar + gerundio", con un porcentaje de aparición de un 5,20\%.

\section{a) Modo indicativo}

Tal como se presenta en el párrafo anterior, las formas más utilizadas por los niños son el presente y el pretérito, en particular el pretérito perfecto simple, datos que coinciden con Aguado (2002), pero con variación en el tipo de pretérito: los niños españoles utilizan el perfecto compuesto 
(he comido), mientras que los costarricenses el perfecto simple (comí), situación encontrada también por Pineda-Morales (2014) con niños venezolanos. Esta diferencia dialectal obedece a una característica del español americano (Cfr. Moreno de Alba, 2001).

Los niños utilizan en su discurso básicamente formas verbales simples; las compuestas son incipientes, aparecen únicamente cinco ejemplos en el corpus ligados a contextos muy específicos y circunscritos a la literatura infantil. Como ilustración los dos ejemplos siguientes:

[1 ] *AM: este cuento se ha acabado!

[2 ] *ADU: y qué le dijo el ratón?

*LAR: que ha e(s)cuchado un rui(d)o.

La expresión 'este cuento se ha acabado' constituye el enunciado de cierre de los cuentos infantiles, tipo de texto habitual en el ambiente preescolar; recuérdese que todos los niños de la muestra asistían a alguna modalidad de Educación Preescolar. Los otros ejemplos encontrados están anclados en discursos pertenecientes a la reconstrucción de un cuento infantil o a la narración de una película. De conformidad con la muestra, en este contexto empiezan a emergen estas formas verbales.

Respecto de las formas progresivas de presente y las de imperfecto, formadas por el verbo "estar + gerundio", se hallaron dieciocho gerundios (lavando, tomando, surfeando, comiendo, empujando, poniendo, llamando, durmiendo, subiendo, llorando, haciendo, viendo, jugando, orinando, echando, lloviendo, bañando, quitando) combinados con las formas de presente estoy, está, estamos, están y de pretérito imperfecto estaba, este último con una frecuencia de dos. La forma más utilizada es "estar haciendo", con las conjugaciones está haciendo, están haciendo, estaba haciendo. A continuación algunos ejemplos:

[3 ] *NIC: (.) qué (es)taba haciendo?

[4 ] *NIC: $\quad$ sí e(s) que estamos viendo esto po(r)que es lindo.

En el presente progresivo se expresa la continuidad del momento en que se realiza la acción; por tanto, en los ejemplos encontrados se utiliza mayoritariamente con verbos de actividad, similar a lo reportado por Aguado (2002).

El tiempo de referencia del niño es el presente, pero este momento de la acción o actividad se expande hacia otros segmentos temporales más cercanos como el futuro próximo, formado mediante la perífrasis "ir a + infinitivo" y el pretérito más inmediato, que ocupa el espacio de lo que 
acaba de suceder: el pretérito perfecto simple. La inmediatez y preeminencia del ahora se ve reflejada en los porcentajes de aparición de esas formas verbales. A continuación algunos ejemplos:

[5 ] *NIC: $\quad$ y ese (.) t(i)ene cascarones y se va a romper ese y xxx.

[6 ] *IGN: voy a deci(r)le a mamá que viene el tiguer [: tigre] [*]

El futuro próximo, tal como puede observarse en esos ejemplos, es realmente una prolongación del presente, pues se refiere a una acción que va a suceder como acto seguido. Estas perífrasis se forman en el corpus con los siguientes verbos de actividad: pasear, buscar, atrapar, correr, decir, dormir, tirar, ir, romper, ver, acercar, mostrar, tapar, sacar, montar, contar, guardar, traer, prestar, echar, nadar y hacer.

Como contraparte el pretérito perfecto simple representa el evento contrario $(21,68 \%$ de representación en el corpus), algo que sucedió antes de la acción presente, como ilustración se encuentran los ejemplos 7 y 8 :

[ 7] *LAR: chí [: sí] [*] [/] (.) la mad(r)a(s)t(r)a che [: se] achutó [: asustó] [*] .

[ 8] *LUC: po(r)que [x 3] la niña la pelli(z)có .

Por su parte, el pretérito imperfecto representa la segunda forma más utilizada del pasado con un $4,91 \%$, el cual se usa mayoritariamente con verbos de actividad y de estado. Este tiempo interesa en su duración y no en su principio ni en su término. Seguidamente ejemplos 9, 10 y 11:

[9] *LAR: no.

*ADU: $\quad$ por qué?

*LAR: no e(s)taba [/] en el sillón.

[10 ] *NIC: dónde estaba ese peyillo [: perrillo] [*] ?

[11] *CAM: (..) cuando estaba pequeno [: pequeño] [*] tenía tos y el do(c)tor lo curó!

De conformidad con lo aquí anotado, se comprueba que el tiempo de referencia del niño es el presente, el cual se extiende hacia el pretérito y el futuro inmediato, mostrando de esta manera el dominio de recursos textuales básicos para comunicarse con sus interlocutores inmediatos.

b) Modo subjuntivo

El modo subjuntivo es muy poco representativo en los niños de este primer tramo de edad. A manera de ejemplo, se citan las formas haga, pelee, vaya, vean que corresponden al subjuntivo, tal como se muestra en el presente caso: 
[12] *CAM: quiero que me haga una bolita.

De acuerdo con Aguado (2002), el uso más frecuente del subjuntivo en los niños de dos años y medio es "como núcleo de predicado de oraciones subordinadas finales: 'espera, espera que se sienten en las sillas / para que coman', 'para que no tengan frío', y comparte esa función sintáctica con frecuentes oraciones de infinitivo" (p. 166). En el caso del corpus del presente trabajo de investigación este modo verbal, ubicado en el terreno de lo supuesto, está representado por las formas vean, vea, cobije, pusieran, subiera, fuera, con una función similar a la encontrada por el autor citado. Sirva el siguiente ejemplo caso:

[13] *ADU: $\quad$ y para qué te echaste agua?

*CAM: porque para que no se me ponieran [: pusieran] [*] azules.

c) Formas no personales

El participio, tal como señala la Nueva Gramática de la Lengua Española (2010), aporta información aspectual y solo indirectamente información temporal. Además, agrega que posee aspecto perfectivo, "lo que permite interpretar la situación que designa como un estadio alcanzado con anterioridad al punto indicado por el verbo principal" (p. 521).

De conformidad con la Nueva Gramática de la Lengua Española (2010), la perífrasis de participio de mayor uso es "estar + participio", la cual designa el estado resultante de una acción o proceso y, por lo general, corresponden a un predicado de realización. No obstante, se señala que las perífrasis de participio son sumamente polémicas y que algunos gramáticos no consideran perífrasis estas construcciones; obviando esas discusiones, la presente investigación únicamente desea describir el uso y las construcciones en que aparece esta forma verbal en el habla infantil.

En el corpus estudiado, el participio se encuentra en construcciones compuestas por "estar + participio", con una función adjetiva en un caso: manzana envenenada.

El participio en el habla infantil representa sucesos recién acontecidos; la perífrasis "estar + participio" responde a la función señalada, o sea el estado resultante de una acción realizada con anterioridad. Seguidamente algunos ejemplos:

[14] *ADU: $\quad$ mirá (.) mirá se me quebró.

*NIC: $\quad$ está yayado [: rayado] [*].

[15] *MIA: vea (.) ta pinta(d)o!

[16] *IGN: $\quad$ sí mucho e(s)tá enamoja:o [: enojado] [*] . 
Respecto del gerundio, interesa particularmente el sentido de duración y su presencia en el discurso infantil, pues evoca acciones que se están realizando o en respuesta, aunque a veces no explícita, a la pregunta ¿qué está haciendo?

[17] *AND: $\quad$ yo [/] voy a hacer un niño xxx jugando.

[18]*IGN: $\quad<\mathrm{A}(1 * \mathrm{ADU}: \quad$ a dónde está?

*LUC: $\quad$ t(r)abajando ic)ia anda (l)imp(i)ando $>[/]$.

Las formas de infinitivo que aparecen conforman oraciones que evocan el inicio de una acción.

[19] *ADU: $\quad$ y qué hace usted aquí?

*CAR: $\quad$ pinta(r) y baila(r).

[20] *ADU: Camila?

*CAM: (.) quiero contar más cuentos!

En síntesis, los tiempos verbales más empleados por los niños de este rango de edad son el presente, el pretérito y la perífrasis de futuro próximo "ir a + infinitivo". Respecto del aspecto, estos niños usan el presente progresivo para evocar la continuidad del momento en que se realiza la acción y dos formas del pretérito: perfecto simple e imperfecto. El niño expresa básicamente "el aquí y el ahora" ligados a las actividades que realiza mediante el juego, la interacción con los adultos cercanos, los tiempos de comida, etc. y también como acciones que se prologan en el tiempo: en un pasado reciente o en un futuro ligado al presente.

\subsubsection{Tipología verbal}

Con el propósito de identificar el tipo de verbo utilizado por los niños de la muestra, tal como se anotó en páginas precedentes, se sigue la taxonomía de Cortés y Vila (1991), basada en Vendler (1967) y usada por Aguado (2002). De esta forma, se tienen verbos de estado y verbos de no estado o dinámicos.

Los verbos de estado describen cualidades o situaciones que no sufren cambios a lo largo del tiempo (estar, tener, gustar, etc.). Los verbos dinámicos describen situaciones que necesariamente comportan un cambio a través del tiempo (construir).

Los verbos dinámicos pueden dividirse en dos clases: de cambio de estado y de actividad. En los verbos de cambio de estado se distinguen dos tipos: puntuales (una vez iniciada la acción no 
se puede parar) y durativos (acción que puede interrumpirse antes de llegar al final). Por su parte, los verbos de actividad implican un cambio de estado, pero no un resultado final (Aguado, 2002, p. $154)$.

Seguidamente, se presenta la clasificación de los treinta verbos más frecuentes, según la taxonomía de referencia.

Verbos de estado: estar, querer, tener, ser, saber, gustar.

Verbos dinámicos de cambio de estado "puntuales": caer, dar, enojar, subir, quitar, pegar, poner, guardar, atrapar.

Verbos dinámicos de actividad: hacer, ver, ir, llamar, jugar, pintar, comer, asustar, pasar, dormir, decir, picar, llover, lavar.

Como puede apreciarse, la mayoría de los verbos son dinámicos de actividad, o sea se refieren a acciones que implican un cambio de estado, pero no un resultado final. Evidentemente, el verbo "haber", por su función de auxiliar en los tiempos compuestos, no es pertinente para el presente estudio.

La abundancia de verbos de actividad en el habla de los niños está relacionada con las características de su discurso oral, el cual se refiere básicamente a las acciones que realizan en el momento de la conversación. Este comportamiento lo encontró Peronard (1981) en Chile "según sus hallazgos, en la edad más temprana, los niños utilizaron solamente verbos de actividad y, posteriormente, verbos desinentes (...)" (citado por Benoit, 2013, p.173).

Por su parte, Aguado (2002) propone que los niños dominan antes los verbos que implican un cambio de estado puntual que los de actividad. Según nuestros datos, los niños costarricenses utilizan con propiedad estos dos tipos de verbos: puntuales y de actividad.

Los hallazgos encontrados para la población chilena infantil y los datos descritos en nuestra muestra denotan coincidencias en el sentido de que los verbos de actividad fueron los más frecuentes y es de esperar que su aparición se diera en un estadio anterior a los verbos que se refieren a una acción acabada o desinente. 


\subsection{Grupo N. ${ }^{0}$ 2: Niños de 2 años y 7 meses a 3 años de edad}

\subsubsection{Tiempos y modos verbales}

El corpus correspondiente a este grupo de edad está formado por 159 verbos con 399 formas verbales conjugadas distintas.

Las formas verbales empleadas por ese grupo de niños se distribuyen de la siguiente forma: a) modo indicativo: presente $37,60 \%$, pretérito perfecto simple $20,30 \%$, pretérito imperfecto 5,76 $\%$, futuro próximo formado por la perífrasis "ir a + infinitivo" 4,25\%; futuro sintético $1,75 \%$; b) modo subjuntivo: presente $1,75 \%$, pretérito imperfecto 2,01\%; c) formas no personales: infinitivo 9,52\% (no se incluyen los infinitivos que forman parte de la perífrasis "ir a + infinitivo"), gerundio $2,51 \%$ y participio pasado $4,01 \%$. Además, se identifica el presente progresivo formado mediante la perífrasis verbal "estar + gerundio", con una frecuencia de un 10,27\%, y se registra una forma en modo condicional.

\section{a) Modo indicativo}

Tal como puede observarse, las formas más utilizadas por los niños son el presente y el pretérito, fundamentalmente el pretérito perfecto simple, datos similares en proporción respecto del grupo anterior. El presente progresivo duplica su presencia respecto de ese grupo, mostrándose como una forma consolidada para expresar una acción presente que se prolonga. El futuro se enriquece con la forma sintética, manteniendo una presencia superior la correspondiente perifrástica.

El uso de formas simples mantiene su preeminencia, pues continúan apareciendo únicamente las formas compuestas en el cierre canónico de los cuentos infantiles "se ha acabado", tal como se muestra a continuación:

[21] *ISA: $\quad$ y había una chiquita que [/] e(s)taba jugando de la cama (.) y viene que me la echó aquí vivía un gusanito que e(s)taba jugando (.) llegó y e(1) cuento se ha acabado.

Las formas progresivas de presente y las de imperfecto, formadas por el verbo "estar + gerundio", duplican su presencia, respecto del grupo anterior. En este corpus aparecen 41 gerundios (jugando, usando, cocinando, poniendo, nadando, haciendo, quedando, picando, durmiendo, quitando, lloviendo, comiendo, soplando, pescando, cantando, pintando, bañando, saliendo, volando, brincando, viendo, buscando, llorando, secando, regando, chorreando, embarrando, roncando, peleando, tomando, arrancando, corriendo, enseñando, trabajando, tocando, quedando, 
parando, cepillando, vistiendo, armando) combinados con las formas de presente estoy, está, estás, están y de pretérito imperfecto estaba y estaban. La forma más utilizada son estar haciendo, estar jugando, estar poniendo, estar durmiendo, estar comiendo. A continuación, algunos ejemplos:

$[22] *$ CAM: $\quad$ porque ta [: está] [*] [/] toviendo [: lloviendo] [*].

[23] *ISA: había una vez que no se e(s)taba un (.) e(s)tá quedándose aquí y había una vez un doso [: oso] [*] que e(s)taba parado de la sala y había una araña que le e(s)taba picando y llegó y le hizo un \&ayayay.

Los ejemplos de las formas progresivas encontradas en el corpus están representados mayoritariamente por verbos de actividad, indicando que se está realizando la acción o que se realizó recientemente.

Pese a que la estrategia principal para que los informantes produjeran texto oral fue la narración, en la cual el pretérito encuentra un terreno fértil para su aparición, el presente es la forma temporal que domina; mas si se suman el presente de indicativo y el presente progresivo, el espacio ocupado por el presente asciende a un $47,87 \%$.

En cuanto al pretérito, el niño emplea los verbos en el perfecto simple, en todas las personas gramaticales (yo, usted/vos, él/ella, nosotros, ustedes, ellos/ellas), con excepción de la primera persona plural. El pensarse como parte de una colectividad (el nosotros) pareciera que todavía no se ha adquirido como competencia en este rango de edad.

A grandes rasgos, el pretérito perfecto simple y el imperfecto mantienen un comportamiento similar respecto del grupo anterior, con porcentajes de aparición de 20,30 \% y 5,76 $\%$, este último representado en las formas verbales: ayudaba, buscaba, comía, echaba, estaba, había, hacía, iba, jugaba, metía, peleaba, podía, quería, quitaba, era, tenía, volaba. A continuación, algunos ejemplos presentes en el corpus:

[24] *ISA: $\quad$ te encont $(\mathbf{r})$ é $<$ a mí $>$ [>].

*ADU: <ahí está: $>[<]$.

*ISA: <a ver si e(s)taba aquí> [?].

[25] *ROD: el diotaurio [: dinosaurio] [*] xxx tomía [: comía] [*] papa $\mathrm{xxx}$ cereala(s).

Respecto del futuro, Ródenas, Brito y Carranza (1991) señalan que: 
Los niños más pequeños utilizan casi exclusivamente el presente, el imperativo y el infinito para mencionar acontecimientos que aún no han sucedido (casi el $90 \%$ de todas las formas verbales de futuro están en presente). Incluso, cuando utilizan el futuro absoluto, no parece tener este tiempo una verdadera connotación temporal de futuro, sino que expresa más bien el deseo de que suceda algo ("Yo te ganaré a ti a correr"; "mi papá me comprará muchos gatitos"). El lenguaje del niño pequeño se encuentra, al parecer, en lo que Smith (1980) ha llamado "el tiempo del suceso" (p. 237).

Una situación similar se encuentra con el uso del futuro en los niños de la muestra: uso del presente, la forma perifrástica y la modesta incorporación del futuro sintético.

\section{b) Modo subjuntivo}

El modo subjuntivo sigue el mismo patrón del grupo anterior, con una frecuencia de uso muy baja. Se utilizan formas de presente y de pretérito imperfecto. El presente, con un tinte de futuro y en el terreno de lo hipotético, se usa en oraciones de finalidad para externar deseos: para que las ardillas sean felices, para que no se ponga triste, para que no suba a la mesa. El pretérito imperfecto en -ra, se usa con las formas comiera, fuera, pusiera y picara como parte de la narración de cuentos infantiles en los que se conjetura sobre acciones que se proyectan a los personajes de los cuales se habla. Aparece también la forma 'vieras', pero con función de conector pragmático. Sirva de ejemplo el siguiente texto:

[26] *ISA: $\quad$ casi se lo coma [: come $\left[{ }^{*}\right]$ ese loso [: oso $\left[{ }^{*}\right][/ /]$ ese lobo

(.) malo (..) y había una vez que al osito (.) no casi no se le picara e(l) pie (.) y e(1) cuento se ha acabado.

\section{c) Formas no personales}

Tal como sucede en el grupo etario anterior, los niños de la presente muestra usan la forma de participio como parte de la perífrasis “estar + participio" (estaba acostado, está enojado, está dormido, está pegada, está quebrado, estaba parado, está mojado); también esa forma verbal se utiliza en función adjetiva. Seguidamente tres ejemplos como muestra:

[27] *ISA: había una vez que no se e(s)taba un (.) e(s)tá quedándose aquí y había una vez un doso [: oso] [*] que e(s)taba parado de la sala y había una araña que le e(s)taba picando y llegó y le hizo un \&ayayay. 
[28] *DAN: e(1) pelo pala(d)o [: parado] [*] porque el pelo parado.

[29] *DAN: la mamá mmm (.) dice que la boca abierta.

El gerundio, por su parte, se utiliza en el tiempo presente para describir y evocar acciones que están en desarrollo. En los ejemplos [30] y [31], a partir del uso de una lámina, el niño caracteriza las acciones o procesos que realizan objetos o seres por describir.

[30] *CAM: u [/] una ardilla u [/] un perro durmiendo solo.

[31] *CAM: una ho(r)miga b(r)i(n)cando e(1) [x 5] pe^rro .

En el mismo contexto de elicitación, la niña del ejemplo 32 caracteriza el sol mediante el uso del gerundio:

[32] *ADU: y qué más?

*DAN: si tie(ne) si (.) no tiene flor.

*DAN: (.) y una nube que linda y brillando el so(l) de las hojas.

También se utiliza el gerundio para evocar acciones que están sucediendo en el momento de la enunciación:

[33] *ADU: qué están haciendo?

*ISA: eh bu(s)cando lib(r)os.

Finalmente, las formas de infinitivo que aparecen en el corpus continúan con el mismo patrón oracional del grupo etario anterior.

Recapitulando, si bien se continúa con el mismo patrón general del grupo anterior: el presente, el pretérito y el futuro perifrástico son los tiempos verbales más empleados, en este grupo se usan, además, con mayor frecuencia y propiedad, formas presentes y futuras del modo subjuntivo; igualmente, se duplica el uso del presente progresivo en la oralización de acciones que se realizan en el momento del habla y en la narración de eventos de los cuentos infantiles evocados por los niños de la muestra.

\subsubsection{Tipología verbal}

La clasificación de los treinta verbos más frecuentes del corpus objeto de estudio sigue el mismo método de análisis señalado para el grupo anterior. A continuación, se transcribe el listado de los verbos seleccionados y su frecuencia: estar (274), ser (196), ir (102), tener (67), caer (60), 
querer (60), comer (59), hacer (57), jugar (57), haber (55), decir (52), mirar (50), ver (39), dormir (35), picar (31), buscar (29), poner (29), tomar (21), perder (20), poder (20), enojar (18), llorar (17), guardar (16), saber (16), salir (16), venir (15), matar (14), acabar (12), dejar (12), romper (11).

Al igual que en el grupo anterior, los verbos "estar" y "ser” ocupan los dos primeros lugares, con frecuencias de 274 y 196, respectivamente. El verbo "estar" presenta seis formas discursivas: está, estaba, estaban, estás, están y estoy, y "ser", ocho formas discursivas: era, eran, es, sean, ser, son, sos, soy.

Seguidamente, se muestra la clasificación de los treinta verbos más frecuentes, según la taxonomía en que se fundamenta esta investigación.

Verbos de estado: estar, querer, tener, poder, ser, saber.

Verbos dinámicos de cambio de estado 'puntuales': acabar, caer, dejar, enojar, guardar, matar, perder, romper, salir.

Verbos dinámicos de actividad: ver, ir, jugar, comer, dormir, decir, llorar, mirar, poner, picar, venir, buscar, tomar, hacer.

Tal como puede observarse, de los 30 verbos, 23 son dinámicos, distribuidos en 9 verbos de cambio de estado y 14 de actividad, reflejando así la caracterización del discurso infantil, o sea, referido normalmente a acciones que se están realizando en el momento de la conversación; de ahí la importancia de que los ambientes de aprendizaje sean enriquecidos con recursos interactivos sugestivos que propicien el desarrollo del lenguaje del niño.

Los verbos de estado, 6 en nuestro corpus, son los que aparecen con mayor frecuencia en el discurso infantil; "estar" y "ser" ocupan las frecuencias más altas (274 y 196, respectivamente), y fueron empleados mayoritariamente en tiempo presente, con porcentajes superiores al $75 \%$ de las veces. Pese a que estos verbos son menos en cantidad al compararlos con los dinámicos, los superan en frecuencia en el discurso infantil.

Respecto de los verbos de cambio de estado, solo aparecen los denominados puntuales, los durativos están ausentes; algo similar encontró Aguado (2002, p. 168), quien señala que "los verbos de cambio de estado durativo no tienen suficiente presencia como para tenerlos en cuenta". El mismo autor indica, respecto de los verbos de estado puntual, que se emplean mayoritariamente en los perfectos compuestos. En el caso de los niños costarricenses, la situación es distinta, ya que el pretérito compuesto tiene una representación mínima y circunscrita a expresiones tomadas de la literatura infantil, sirva como ejemplo el canónico "ha acabado" para referirse al cierre de los 
cuentos infantiles, con una frecuencia de 11 apariciones. En el caso del resto de los verbos, se utilizan mayoritariamente en pretérito perfecto simple y en presente.

\subsection{Grupo N..$^{\circ}$ 3: Niños de 3 años a 3 años y 6 meses}

\subsubsection{Tiempos y modos verbales}

El corpus correspondiente a este grupo de edad está formado por 108 verbos con 237 formas verbales conjugadas distintas.

Las formas verbales de discurso se distribuyen de la siguiente forma: a) modo indicativo: presente $45,57 \%$, pretérito perfecto $18,99 \%$, pretérito imperfecto $5,48 \%$, futuro próximo formado por la perífrasis "ir a + infinitivo" $3,80 \%$; b) modo subjuntivo: presente $0,84 \%$, pretérito imperfecto $0,84 \%$; c) formas no personales: infinitivo $11,81 \%$ (no se incluyen los infinitivos que forman parte de la perífrasis "ir a + infinitivo"), gerundio 3,36 \% y participio pasado 5,48 \%. El presente y el imperfecto progresivo, formado mediante la perífrasis verbal "estar + gerundio", aparece con una presencia de un 5,06\%.

\section{a) Modo indicativo}

Se mantiene el patrón encontrado en los grupos anteriores: el presente y el pretérito son los tiempos verbales más frecuentes en el habla infantil. En términos generales, el comportamiento porcentual es muy similar al de los niños de dos años; habría que analizar con mayor profundidad la adecuación en el uso de las formas verbales y la formación apropiada de los verbos irregulares, tareas que quedan pendientes para otra investigación.

Las formas compuestas siguen siendo incipientes, ya que aparecen únicamente dos casos, los cuales se presentan a continuación:

[34] *DAN: $\quad$ colorín colorado (.) este cuento se ha terminado.

[35] *THI: $\quad<$ ya voy> [/] es que todavía no he servido el sirope.

En el primer caso se trata de la ya presentada fórmula de cierre de los cuentos infantiles y en el segundo, un enunciado presente en un juego de representación de roles, en la denominada "casita" o área de dramatizaciones en los jardines infantiles. El primer ejemplo con una frecuencia de cinco y el segundo de uno, o sea, solamente fue usado por un niño de la muestra.

Las formas de presente y de imperfecto progresivas, formadas por "estar + gerundio", mantienen su presencia con una representación del 5,06\%. Los verbos que participan en la 
formación de estas perífrasis son verbos de actividad (echando, leyendo, llorando, durmiendo, caminando, volando, cocinando, sembrando, haciendo, moviendo, riendo y volando), combinados con las formas gramaticales estoy, está, estaba y estaban. A continuación como muestra el siguiente ejemplo:

[36] *GAB: y los [//] y el osito estaba leyendo un cuento (.) de caminando la bruja (.) la casa de (.) o (.) de este osito.

Siguiendo con el modo indicativo, el pretérito presenta una estructura esperada: el perfecto simple porcentualmente sobresale respecto del imperfecto, siguiendo un modelo regular en el habla de los niños costarricenses.

Las 45 formas verbales en pretérito perfecto simple que aparecen en el corpus representan mayoritariamente verbos dinámicos de actividad (golpeó, gritó, dijo, fue, llevaron, salté, etc.) y de cambio de estado del tipo puntuales (cayó, acabó, arrancó, enojó, sentó, olvidó).

Respecto del futuro, se continúa con el patrón de los grupos anteriores: el uso único del futuro próximo formado mediante la perífrasis "ir a + infinitivo". A continuación algunos ejemplos:

[37]*VIC: le voy a poner un nombre.

[38]*THI: $\quad$ digamos (.) pue (.) xxx puedo ir a jugar con [x 3] este gatito (.)

[39]* VIC: una casita voy a hacer.

$[40]^{* *}$ GAB: $\quad$ yo lo voy a t(r)aer en (.) la mañana

[41]*VIC: quién van a vivir aquí?

Los ejemplos 37, 38 y 39 evidencian una prolongación del presente, se refieren a una acción que va a suceder como acto seguido; mientras que los ejemplos 40 y 41 se refieren a un futuro próximo e inminente.

\section{b) Modo subjuntivo}

En este grupo de edad solamente una niña utiliza este modo verbal en dos ocasiones para referirse a una proyección futura, tal como se muestra a continuación:

$$
\begin{aligned}
{[42] * \text { VIC: } } & \text { sí }[/ / /] \text { no. } \\
\text { *ADU: } & \text { no? } \\
\text { *VIC: } & \text { cuando sea Navidad. } \\
\text { *ADU: } & \mathrm{y}<\text { usted }>[/] \text { ayuda a mamá a poner el arbolito? }
\end{aligned}
$$


*VIC: $\quad$ mmm no porque (es)tá mu(y) pesado.

[43]*VIC: $\quad$ se roba a Rapunzel.

*VIC: $\quad$ y entonces en un castillo.

*VIC: $\quad$ y de(s)pués (.) cuando sea gran:de (.) Rapunzel (.) <manejó> [?].

*VIC: $\quad$ y [/] se cayó la bruja.

*VIC: $\quad$ y solo quedó la campa.

\section{c) Formas no personales}

Las formas no personales infinitivo, gerundio y participio, con una presencia respectiva de $11,81 \%, 3,36 \%$ y $5,48 \%$, se usan con las mismas funciones encontradas en los casos anteriores. En lo concerniente al participio, se mantiene primordialmente el uso como parte de la perífrasis "estar + participio" y también en función adjetiva. El gerundio se utiliza, en la mayoría de los casos, para describir y evocar acciones que están sucediendo en el presente. El infinitivo se empieza a utilizar en función sustantiva y en oraciones que evocan el inicio de un proceso.

\subsubsection{Tipología verbal}

Continuando con el mismo procedimiento metodológico aplicado para los grupos anteriores, se identifica la tipología verbal de los treinta verbos más frecuentes usados por los informantes de este rango de edad. Los verbos objeto de estudio con su respectiva frecuencia son: ser (91), estar (72), ir (40), tener (33), hacer (22), decir (19), haber (17), encontrar (16), ver (15), querer (15), poder (13), comer (13), jugar (12), cocinar (12), contar (11), pintar (11), correr (10), orinar (10), poner (10), gustar (9), volar (9), asustar (9), saltar (7), caer (6), dar (6), dormir (6), faltar (6), pasear (6), traer (5) y venir (5).

Los verbos de estado "estar" y "ser" ocupan los primeros lugares en frecuencia de aparición en el corpus, situación explicable por su función de nexo de unión entre dos significados: el atributo y el sujeto.

El verbo "estar" presenta ocho formas discursivas distintas: está, estaba, estaban, estás, estamos, están, estar y estoy. A fin de ilustrar los contextos de uso se muestran los siguientes fragmentos como ejemplos:

[44] *GAB: (.) la bruja (.) estaba aquí (.) echando un poquito aquí. 
[45] *DAN: una (texto incomprensible) que están [//] que estaban volando.

El verbo "ser", por su parte, presenta seis formas discursivas: era, eran, es, sea, son y soy. De estas, la que tiene una mayor frecuencia es la forma presente, con 63 apariciones.

Seguidamente, se presenta los fragmentos 48 y 49 con ejemplos del uso de este verbo.

[46] *VIC: $\quad$ sabe (texto incomprensible) amigos es Valeria Mónica.

[47] *VIC: $\quad$ cuando sea Navidad.

Respecto de la taxonomía en que se sustenta esta investigación, se presenta la clasificación de los treinta verbos más frecuentes:

Verbos de estado: estar, querer, tener, poder, ser, gustar.

Verbos dinámicos de actividad: ver, ir, decir, comer, jugar, cocinar, pasear, traer, venir, contar, pintar, correr, volar, saltar, dormir, asustar, hacer.

Verbos dinámicos de cambio de estado puntuales: caer, orinar, encontrar, poner, dar.

Los verbos de actividad constituyen el 63,33\% del total de verbos con mayor frecuencia de uso en el corpus, seguidos de los verbos de estado y, finalmente, de los puntuales. Sin embargo, si se considera la frecuencia de aparición de estos verbos, con sus respectivas conjugaciones, los más usados en el discurso son los verbos de estado, los cuales aparecen en los primeros diez lugares respecto de la variable frecuencia de aparición, con excepción del verbo "gustar"; ello sin duda por la función sintáctica de vínculo de los verbos "ser" y "estar".

\subsection{Grupo N. ${ }^{\circ}$ 4: Niños de 3 años y 7 meses a 4 años de edad}

\subsubsection{Tiempos y modos verbales}

El corpus correspondiente a este grupo fue aportado por 13 niños y está formado por 215 verbos con 602 formas verbales conjugadas distintas.

El tiempo en que discurre la noción expresada mediante morfemas verbales se resume de la siguiente forma: a) modo indicativo: presente $35,55 \%$, pretérito perfecto simple 23,59\%, pretérito imperfecto $5,48 \%$, futuro próximo formado por la perífrasis “ir a + infinitivo" $10,13 \%$, futuro sintético $0,83 \%$; b) modo subjuntivo: presente $4,17 \%$, pretérito imperfecto $1,16 \%$; c) formas no personales: infinitivo $5,48 \%$ (en este porcentaje no se incluyen los infinitivos que forman parte de la perífrasis "ir a", pero sí en las colocaciones con los verbos querer y poder o en función 
sustantiva), gerundio $1,83 \%$ y participio pasado 3,16\%. Además, se identificó la presencia del presente progresivo con una presencia de un 3,49\% y el imperfecto progresivo con el mismo porcentaje, formados mediante la perífrasis verbal "estar + gerundio".

a) Modo indicativo

Las formas de presente, pretérito perfecto simple y futuro próximo ocupan los porcentajes superiores, en este tramo de edad. Este grupo, respecto de los anteriores, presenta un aumento significativo en el uso de la perífrasis que forma el futuro próximo y en el uso del imperfecto progresivo, muy ligado a la narración de eventos sucedidos en cuentos infantiles que sirvieron, como estrategia de elicitación, para obtener los corpus orales recolectados. Algunos ejemplos son:

[48] *SAU: $\quad$ y había un chancho (.) estaba haciendo un $<\mathrm{mmm}>$ [x 3].

[49] *SAN: $\quad$ y entonces (.) el lo(bo) (.) estaba persiguiéndolos (.) así.

En los ejemplos anteriores, los dos niños citados narraron el cuento "Los tres cerditos", muy conocido en el ámbito infantil, y, por tanto, debían referirse a acciones acaecidas durante un tiempo que se prolongó en el pasado, como por ejemplo hacer una casa o perseguir reiteradamente a alguien, una de las acciones principales del lobo en este relato infantil.

El imperfecto progresivo también se usa para referirse a acciones muy cercanas al presente, tal como se muestra continuación:

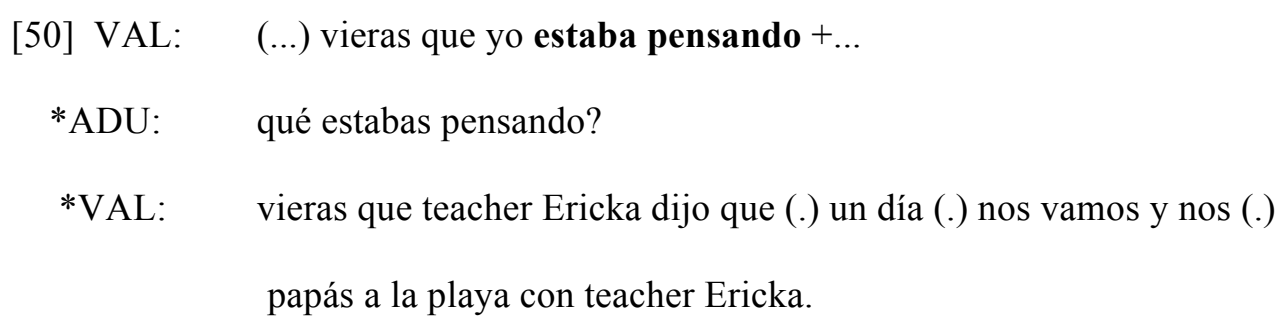

[51] *TAM: Marcela, yo estaba usando este, Marcela (.) Marce, yo estaba usando este!

La primera parte del ejemplo 50 es un recurso enfático para iniciar una conversación, y el 51 se produce en el contexto de un reproche: una niña toma un objeto que otra estaba usando, sin su consentimiento. En virtud de estos ejemplos, el uso de esta forma temporal está bien posesionada en el habla infantil.

El uso del pretérito imperfecto está ligado básicamente a los verbos estar (estaba, estaban, estábamos), ser (era, eran), ir (iba, ibamos), tener (tenía, teníamos, tenían), agarrar (agarraban, 
agarraba), comer (comía), dar (daba), decir (decía), escuchar (escuchaba), faltar (faltaba), gustar (gustaba), haber (habia), hacer (hacia), jalar (jalaba), llamar (llamaba), llevar (llevaba), poder (podia), quedar (quedaba), querer (quería), saber (sabia), salir (salia), sonreír (sonreía), usar (usabas), ver (veía) y vivir (vivian). Según Villamil-Forastieri (1991), el empleo del imperfecto durante el proceso de narrar cuentos sugiere un mundo de juego y de ficción. Este uso se ve reflejado en las muestras de habla de los niños costarricenses, principalmente en los segmentos narrativos.

Respecto de los verbos copulativos, empleados con frecuencias muy altas en nuestro corpus, Sera (1992) y Sera y otros (1997), citado por Bel Gaya (2013) señalan que en producciones espontáneas de niños en torno a los tres años las cópulas se emplean de modo adecuado y con distintos elementos: adjetivos, nominales, locativos, además de su uso en la construcción progresiva. Este recurso se corrobora en las muestras de habla de niños costarricenses.

En relación con el futuro, aparece la forma sintética estarán en el enunciado y qué estarán viendo, el cual se produce en virtud de la repetición por parte del niño del mismo enunciado emitido por el adulto que lo acompañaba, no como una forma de producción espontánea. La expresión y qué estarán viendo es una forma verbal futura, pero con un valor de conjetura en el presente. Este ejemplo sirva como muestra del proceso de adquisición de la lengua: la repetición del modelo verbal del adulto.

El futuro perifrástico presenta un comportamiento similar al hallado en los otros grupos; sirvan de ejemplo los siguientes casos:

\section{[52] *TAM: pero es que le voy a poner crema.}

En el ejemplo 52, la acción futura de la niña es una continuación de la actividad presente, pero en los siguientes casos se observa un futuro menos inmediato:

[53]*SAU: $\quad$ y también me van a comprar una pista grande.

[54] *VAL: $\quad$ Santa me va a traer una bicicleta (.) rosado (.) morado (.) y turquesa...

[55]*VAL: $\quad$ se me hace de día y no puedo [/] y no [/] y no puedo ver la película toda porque se me hace de día y voy a estar cansada.

Los ejemplos 53 y 54 son típicos en el discurso del niño que espera juguetes u otro bien a corto plazo o cuando una festividad se aproxima, pero el caso número 58 es un poco distinto porque es una proyección clara de un estado físico que experimentará la niña después de transcurrido cierto 
tiempo. De igual manera, se encuentra el uso de la construcción "ir a + infinitivo" en pretérito, tal como se muestra a continuación:

[56]*AUR: $\quad$ y entonces se fue solo al jardín a bincal [: brincar] [*] en el t(r)ampolín.

\section{b. Modo subjuntivo}

Este cuarto grupo de niños de tres años y siete meses a cuatro años es el que presenta una mayor frecuencia en el uso del subjuntivo, tanto en presente como en pretérito; lo anterior muestra que este modo verbal se va adquiriendo más tardíamente para expresar eventualidades u otras situaciones que se desea que no suceden o no hayan sucedido, ligadas generalmente a la narración de cuentos infantiles o programas de televisión. En el caso de este corpus, el deseo de que el lobo feroz no atrape a los cerditos o, con el mismo sentido, que los pitufos logren escapar.

[57] *ISA: $\quad<$ y después $>[<]$ (.) dijo "espero que el lobo feroz no los atrape".

*ISA: (.) otro <se construyó> [?] una casa de paja.

*ISA: $\quad$ otro de madera.

[58] *ADU: esa tampoco la he visto.

*VAL: $\quad$ es que los pitufos [/] los pituf [/] los pitufos son $+\ldots$

*VAL: que (.) corren para que no lo atrape.

*VAL: $\quad$ y Tontín se va a caer a la cascada.

Los deseos de que el futuro atraiga tiempos mejores se manifiesta mediante presente de subjuntivo:

[59] *SEB: un dí (.) un día que tengamos mucha $\mathrm{p}(1)$ atita vamos a ir a Disney.

*ADU: $\quad$ en serio (.) querés ir a Disney?

El subjuntivo se usa también para denotar duda, intenciones, tal como se muestra a continuación:

[60] *ISA: $\quad$ no creo que us^te:(d) (.) se levante.

[61] *TAM: esto [/] es para [/] esto es para que ella no [/] para que no le duela (.) la cabecita.

[62] *VAL: $\quad$ y una peluca de Ariel que se pueda meter en el agua. 
*VAL: $\quad$ para (.) que pueda hacer [//] para que pueda nadar en piscina.

El pretérito imperfecto de subjuntivo también se usa con mayor frecuencia respecto de los grupos anteriores; con esta forma el niño manifiesta la posibilidad de asumir un rol que realmente no le pertenece: como si yo fuera o como si ellos fueran otra cosa o persona. Así se observa en los ejemplos:

[63] *VAL: $\quad$ vieras que (.) Amelia la muñeca lloraba.

*VAL: $\quad$ y esto como si yo fuera la mamá de ella.

[64] *VAL: $\quad$ le pegué unos (.) uno (.) unos papelitos que no se ven.

*VAL: como si fueran invisibles.

Además de la función anterior, aparece el imperfecto simple de subjuntivo en la forma viniera y corriera, usados con la intención de que el oyente interprete que otra persona es la responsable de la acción presentada, en este caso venir y correr; como en los ejemplos:

[65] *SAU: $\quad$ porque mi papá (.) me dijo que viniera a este kínder.

*SAU: $\quad$ y después cuando sea más grande voy a venir a otro kínder.

[66] *ADU: (.) qué están haciendo aquí?

*AME: corriendo.

*AME: le dijo que corriera.

b) Formas no personales del verbo

Respecto de las formas no personales, se continúa con el mismo patrón encontrado en los grupos anteriores. El participio pasado aparece formando la perífrasis "estar + participio"; como interjección para llamar la atención: ¡animales, cuidado, aquí viene el agua!, y en una colocación frecuente del verbo poner con el participio enojado: ponerse enojado.

El gerundio sigue siendo utilizado para describir y evocar acciones que están en desarrollo. Por otra parte, el infinitivo aparece en oraciones que evocan el inicio de una acción o de una cosa, tal como se muestra en el ejemplo 67, pero también para indicar finalidad o proyección, precedido de la preposición "para", según el ejemplo 68.

[67]*FEL: quiero abrir eso. 
[68]*VAL: $\quad$ y después Gargamel hace una poción para atrapar algún pitufo.

Si bien este cuarto grupo de niños mantiene como patrón general de la prevalencia de presente, pretérito y futuro próximo como formas temporales básicas, se da un aumento significativo del uso del futuro analítico y del imperfecto progresivo de indicativo, hasta igualarse porcentualmente con la forma correspondiente al presente.

\subsubsection{Tipología verbal}

Con el propósito de identificar la tipología verbal de los treinta verbos más frecuentes usados por los niños en el corpus objeto de estudio, de conformidad con la taxonomía de Cortés y Vila (1991), basada en Vendler (1967) y usada por Aguado (2002), se presentan los verbos seleccionados con su respectiva frecuencia, colocada entre paréntesis: ser (370), estar (207), hacer (185), ir (148), jugar (135), tener (126), ver (112), saber (88), llamar (64), comer (59), haber (55), decir (52), querer (40), poder (39), mirar (38), poner (37), dar (27), meter (25), venir (22), acabar (21), dormir (18) contar (15), encontrar (16), salir (16), soplar (16), compartir (16), correr (14), oler (13), crecer (12) y creer (12).

En el listado anterior se puede observar que al igual que en el grupo etario anterior, los verbos "ser" y "estar" ocupan los dos primeros lugares, con frecuencias de 370 y 207 , respectivamente.

El verbo "estar" presenta once formas discursivas: estaba (53), estaban (32), estábamos (1), estar (18), estarán (1), estamos (1), estoy (9), está (70), están (20), estás (1), estuvo (1). Para el verbo "ser" se consignan ocho formas discursivas: era, eran, es, sea, sean, somos, son, soy. De estas, la que tiene una mayor frecuencia es la forma en presente, con 273 repeticiones, manifestándose así la preeminencia del presente, respecto de las otras formas temporales.

En relación con la función de la noción verbal, se presenta la clasificación de los treinta verbos más frecuentes, según la taxonomía de referencia en esta investigación.

Verbos de estado: estar, saber, querer, poder, ser, tener, compartir, creer.

Verbos dinámicos de cambio de estado 'puntual: meter, acabar, encontrar, salir, dar, poner.

Verbos dinámicos de actividad: ir, jugar, ver, llamar, comer, decir, mirar, venir, dormir, contar, soplar, correr, oler, crecer, hacer. 
De esos 30 verbos, 15 son verbos de actividad, 6 puntuales y 9 de estado (se omite el verbo "haber" por su función básica de auxiliar) caracterizando una vez más el discurso infantil, en el cual es prototípico el conversar acerca de las actividades que se están realizando en el momento de la emisión oral.

\section{Conclusiones}

En los cuatro grupos de niños se identifican los verbos "ser" y "estar" con las frecuencias más altas, lo que coincide con lo encontrado por Cano et al. (2011) en un estudio con niños españoles de 2 a 3 años, pues esos mismos verbos encabezan la lista de frecuencia.

Los tiempos verbales más ampliamente usados son el presente, el pretérito perfecto simple y la perífrasis con valor de futuro "ir a + infinitivo". Mediante estos tiempos el niño expresa lo experimentado en el momento actual, el presente representa el aqui y el ahora, las otras dos formas un pasado y un futuro todavía ligados al presente.

A los dos años, los niños ya han adquirido la categoría de verbo y a partir de ese momento se empieza a ampliar el repertorio hasta lograr flexiones en todas las personas después del tercer año.

Del modo indicativo se comprueba que el niño entre los 2 y 4 años utiliza formas de presente, pretérito perfecto simple, pretérito imperfecto, futuro analítico y sintético. Los tiempos compuestos son incipientes y están ligados a narraciones de textos literarios y a colocaciones muy específicas como este cuento se ha acabado.

El modo subjuntivo, ubicado en el ámbito de lo supuesto, de la proyección mental, es de adquisición más tardía y su representación en el texto oral infantil se circunscribe a oraciones finales precedidas de la preposición "para", con un sentido de futuro, como forma para expresar deseos y conjeturas proyectadas hacia los personajes de cuentos infantiles. En este modo verbal el niño utiliza únicamente algunas formas de presente y de pretérito.

El aspecto verbal se ve representado en esta muestra por la perífrasis "estar + gerundio" y las dos realizaciones del pretérito: perfecto simple e imperfecto. Esos usos ya están presentes en el habla de los niños desde los dos años.

Respecto de la función verbal, los datos obtenidos son coincidentes con los encontrados por autores como Aguado (2002) y Cortés y Vila (1991), en el sentido de la preeminencia de los verbos 
de actividad, asociados al presente y a las formas progresivas, frente a los de cambio de estado puntuales y de estado.

\section{Referencias bibliográficas}

Aguado, Gerardo. (2002). El desarrollo del lenguaje de 0 a 3 años. Madrid: CEPE, S. L.

Benoit, Claudine. (2013). Tiempos y formas verbales en la producción oral de un grupo de preescolares y escolares de primer año básico. Literatura y Lingüística, XXVIII, 169-191. Recuperado de $\quad<$ http://www.scielo.cl/scielo.php?script=sci_arttext\&pid=S0716$58112013000200010>$

Bel-Gaya, Aurora. (2013). Omisión y selección de la cópula en el desarrollo del lenguaje. Revista Española de Lingüística, XLIII(2), 63-90. Recuperado de $<$ http://sel.edu.es/rsel/index.php/revista/article/view/109/100>

Berman, Ruth y Slobin, Dan Isaac. (1994). Relating narrative events: A crosslinguistic developmental study. Hillsdale, New Jersey: Lawrence Erlbaum Associates.

Cano, Pablo, Fernández, Isabel y González, Miguel. (2011). Características construccionales en el corpus Koiné y emergencia de la gramática. En Milagros Fernández (Ed.), Lingüistica de corpus y adquisición de la lengua (pp. 87-147).

Cortés, Monserrat y Vila, Ignasi. (1991). Uso y función de las formas temporales en el habla infantil. Infancia y Aprendizaje, LIII, 17-43. Recuperado de $<$ https://dialnet.unirioja.es/servlet/articulo? codigo $=48360>$

Fernández-Pérez, Milagros. (2006). Usos verbales y adquisición de la gramática. Construcciones y procesos en el habla infantil. Revista Española de Lingüistica (RSEL), VII, 319-347. Recuperado de $<$ http://www.sel.edu.es/pdf/ene-dic-06/RSEL-36-Fernandez.pdf $>$

Gili, Samuel. (1972). Estudios de lenguaje infantil. Barcelona: Vox.

Moreno de Alba, José G. (2001). El español de América. México: Fondo de Cultura Económica.

Pineda-Morales, Lisset. (2014). El tiempo y el aspecto en el español temprano de Venezuela y España (Tesis de doctorado). Universidad de Salamanca.

Prago, Gabriela. (2004). Narraciones de niños de 3 y 4 años: un puente entre la gramática y la pragmática. En Montserrat Vyrat y Beatriz Gallardo (Eds.), Estudios de Lingüistica Clínica (pp. 99-126). 
Real Academia Española y Asociación de Academias de la Lengua Española. (2010). Nueva Gramática de la Lengua Española. Manual. Madrid: Espasa.

Rodenas, Antonio; Brito, Alfredo y Carranza, José. (1991). La referencia temporal de futuro en el lenguaje espontáneo infantil. Anales de Psicología, VII(2), 225-241. Recuperado de $<\mathrm{http}: / /$ www.um.es/analesps/v07/v07_2/09-07_2.pdf $>$

Sebastián, Eugenia. (1991). El desarrollo del sistema de referencia temporal en español: Un paseo por la morfología verbal. Anales de Psicología, VII(2), 181-196. Recuperado de https://www.researchgate.net/publication/43976145_El_desarrollo_del_sistema_de_referen cia_temporal_en_espanol_un_paseo_por_la_morfologia_verbal

Smith, Carlota. (1980). The acquisition of time talk: relations between child and adult grammars. Journal of Child Language, 7, 263-278. Recuperado de https://www.cambridge.org/core/journals/journal-of-child-language/article/acquisition-oftime-talk-relations-between-child-and-adultgrammars/53FB97E2CCB101662900BFBC36DFD0DE [Consulta 10 de agosto de 2016].

Villamil-Forastieri, Blanca. (1991). La adquisición de aspecto y tiempo en niños puertorriqueños entre las edades de 1; 10 a 3; 2 años. En Humberto López Morales (Ed.), La enseñanza del español como lengua materna (pp. 199-212).

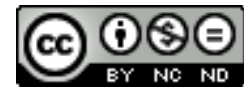

Esta obra está bajo una licencia de Creative Commons Reconocimiento-NoComercial-

SinObraDerivada 4.0 Internacional 